\title{
Novel Benzimidazole Bejeweled Pyrazole: Synthesis, Characterization and Density Functional Theory Analysis
}

\author{
Ramar Sivaramakarthikeyan, Krishnaraj Padmavathy, Vadivel Saravanan, \\ Chennan Ramalingan
}

\begin{abstract}
A novel benzimidazole festooned pyrazolyl acrylonitrile 6 has been synthesized with a good yield via Knoevenagel condensation method and the structure has been elucidated based on analytical and spectroscopic methods. DFT-B3LYP calculation with 6-311 G(d,p) basis set has been performed for optimization of the structure and to determine their structural - energy parameters. The HOMO -LUMO analysis and polarizability cum hyper polarizability values ensure compound 6 is likely to be NLO material that could also find use in solar cells. Besides, the electronic properties and the structural cores imply that the molecule could also serve as bioagent.
\end{abstract}

Keywords: Knoevenagel condensation, DFT, NLO, pyrazole, benzimidazole.

\section{INTRODUCTION}

Most of the biologically energetic compounds comprise of nitrogen heterocyclic frame work. Nitrogen heterocycles find applications in pharmaceuticals and agrochemicals [1]. Pyrazole is one such heterocycle with two adjacent nitrogen atoms in aromatic five-membered ring structure [2]. Pyrazole derivatives show extensive bio-potent activities such as antimicrobial [3], antirheumatic [4-6], anti-inflammatory [7-9], anticancer [10], radio protective [11], antiproliferative [12], and anti-tuberculosis [13]. Few pyrazoles were reported to display photosynthetic electron transport inhibition properties [14]. Certain Ir(III) complexes (sublimable and cationic) possessing pyrazole-based ligands were proved to be promising blue-green-emitting OLED [Quantum efficiency - 5.9\%; $(0.19,0.30)$ color coordinates \& $11.3 \%$; $(0.27,0.50)$ color coordinates] [15]. Norbornene category of

Revised Manuscript Received on December 15, 2019.

* Correspondence Author

Ramar Sivaramakarthikeyan, Department of Chemistry, School of Advanced Sciences, Kalasalingam Academy of Research and Education (Deemed to be University), Krishnankoil, 626 126, Tamilnadu, India. Email: sivaram.ramar@gmail.com

Krishnaraj Padmavathy, Department of Chemistry, School of Advanced Sciences, Kalasalingam Academy of Research and Education (Deemed to be University), Krishnankoil, 626 126, Tamilnadu, India. Email: ovshada@gmail.com

Vadivel Saravanan, Department of Chemistry, School of Advanced Sciences, Kalasalingam Academy of Research and Education (Deemed to be University), Krishnankoil, $626 \quad 126, \quad$ Tamilnadu, $\quad$ India. Email: saravananvj11@gmail.com

* Chennan Ramalingan, Department of Chemistry, School of Advanced Sciences, Kalasalingam Academy of Research and Education (Deemed to be University), Krishnankoil, $626 \quad 126$, Tamilnadu, India. Email: ramalinganc@gmail.com

copolymers possessing dialkylpyrazole motif were reported to be efficient in stabilizing in-situ produced magnetite nanoparticles [16]. Besides these, they also find applications in semiconductors [17], solar cells [18] and liquid crystals [19]. Benzimidazole is yet another nitrogen heterocyclic compound with fused benzene and imidazole rings. It exhibits wide spread biological activities such as antimicrobial [20], antihistaminic [21], antiparasitic [22], antiallergic [23], anticancer [24] and antioxidant [25]. In addition, its derivatives display efficiency in material science field. Specifically, benzimidazole containing sulfonated polyethersulfones displayed high IEC and proton conductivity value with low swelling ratios, promising a worthy role towards proton exchange membrane applications [26]. The supramolecular assembly of benzimidazole derivatives is reported to find application in sensor fabrication [27], drug delivery systems [28], and fuel cell design [29].

In view on the above-mentioned potential applications, a molecule containing both the pyrazole and imidazole motifs has been designed to synthesize for various applications. This piece of work depicts synthesis and characterization of novel benzimidazole integrated pyrazolyl acrylonitrile 6 . This novel compound has been optimized utilizing DFT-B3LYP [6-311G (d,p)]. Further, quantum chemical parameters such as molecular geometry, HOMO-LUMO, MEP, Mulliken charge distribution and NLO properties of synthesized molecule have also been determined.

\section{EXPERIMENTAL SECTION}

\section{A. General}

All reactants / reagents used in the present study are reagent grade and the solvents were distilled prior to use. TLC and open capillary were used to observe the reactions progress and to measure the melting point, respectively. Shimadzu IR Tracer-100 spectrophotometer and Bruker AVANCE III NMR spectrometer were utilized for recording IR and NMR spectra, respectively.

\section{B. Synthesis of carbaldehyde 4 [30]}

A mixture of ketone $\mathbf{1}(0.01 \mathrm{~mol})$ and hydrazine $2(0.01$ mol) in $10 \mathrm{ml}$ glacial acetic acid was heated at $80{ }^{\circ} \mathrm{C}$ for 30 minutes. Filtered the reaction mixture after cooling, washed the solid (3) thus obtained using dil. $\mathrm{HCl}$ solution and recrystallized from ethanol. 


\section{Novel Benzimidazole Bejeweled Pyrazole: Synthesis, Characterization and Density Functional Theory Analysis}

Pure arylhydrazone obtained was treated with Vilsmeier-Haack reagent [DMF $\left.(10 \mathrm{ml})-\mathrm{POCl}_{3}(0.03 \mathrm{~mol})\right]$ at $0{ }^{\circ} \mathrm{C}$ and it was heated at $70-80{ }^{\circ} \mathrm{C}$ for $6 \mathrm{~h}$. It was then brought in to RT and then poured in to cold water. After neutralization using saturated solution of sodium bicarbonate, followed by washing and drying, the solid thus obtained was recrystallized from ethanol to give pure product 4 .

\section{Synthesis of novel acrylonitrile 6}

To a methanolic mixture of carbaldehyde $4(0.5 \mathrm{~g}, 1.58$ $\mathrm{mmol}$ ) and imidazolyl acetonitrile 5 (0.25 g, $1.58 \mathrm{mmol})$, was added piperidine $(0.16 \mathrm{ml}, 1.58 \mathrm{mmol})$ dropwise. It was stirred at $60{ }^{\circ} \mathrm{C}$ for $6 \mathrm{~h}$. After completion of the reaction, it was poured into water (ice-cold). A saturated solution of potassium carbonate was then added drop-wise until neutralization. It was filtered, washed (water), dried and recrystallized (ethanol) to give pure target compound 6 . Yield, $89 \%$; MP: $310-311^{\circ} \mathrm{C}$; FT-IR $\left(\mathrm{KBr}, \mathrm{cm}^{-1}\right): v 3290.4$, 2240.1, 1600.7, 1531.3, 1418.1, 1355.3, 1244.5, 1111.2, 1052.7, 969.6, 856.5, 813.3, 757.0, 677.7, 663.5, 635.3, 497.6; ${ }^{1} \mathrm{H}$ NMR $\left(400 \mathrm{MHz}, \mathrm{CDCl}_{3}\right): \delta 8.76(\mathrm{~d}, J=8 \mathrm{~Hz}, 2 \mathrm{H})$, $8.6(\mathrm{~s}, 1 \mathrm{H}), 7.77-7.64(\mathrm{~m}, 5 \mathrm{H}), 7.52-7.42(\mathrm{~m}, 3 \mathrm{H}), 7.36(\mathrm{t}, J=$ $8 \mathrm{~Hz}, 1 \mathrm{H}), 7.28(\mathrm{~s}, 2 \mathrm{H}), 5.24(\mathrm{~s}, 1 \mathrm{H}) \mathrm{ppm} ;{ }^{13} \mathrm{C}$ NMR $(100$ $\left.\mathrm{MHz}, \mathrm{CDCl}_{3}\right)$ : $\delta$ ppm 180.1, 136.1, 129.8, 129.6, 129.3, $127.2,125.5,123.8,119.1 \mathrm{ppm}$.

\section{Computational details}

The entire set of calculations of $\mathbf{6}$ has been made by exploiting DFT-B3LYP (6-311G (d,p) method [Gaussian 09 program] [31]. The DFT-B3LYP is a universally accepted cheap method of computation for structural optimization [32]. Optimized molecular geometry, HOMO-LUMO energy calculations, MEP, Mulliken atomic charge distributions and NLO properties of the compound $\mathbf{6}$ were acquired from the above computational method.

\section{RESULTS AND DISCUSSION}

\section{Chemistry}

\section{A. Synthesis and characterization}

The phenyl hydrazone derivatization of 1-(2,4-dichlorophenyl)ethanone $\mathbf{1}$, followed by cyclization and formylation using Vilsmeier Haack reagent yielded the carbaldehyde intermediate 4. Knoevenagel condensation between the carbaldehyde $\mathbf{4}$ and benzimidazolyl acetonitrile 5 using piperidine as catalyst eventually rendered the target acrylonitrile 6 as shown in Scheme 1. The absence of characteristic vibrational frequency in the region of carbonyl absorption in the IR spectrum and absence of one proton singlet in the aldehydic proton region $(\sim \delta 9.5 \mathrm{ppm})$ in the ${ }^{1} \mathrm{H}$ NMR spectrum and the presence of medium peak at 2240 $\mathrm{cm}^{-1}$, consistent to nitrile group, confirms the target compound. The proton and carbon spectra agreed well with the structure of target molecule $\mathbf{6}$.

\section{B. Geometry Optimization}

The structural optimization of compound $\mathbf{6}$ was made using computational DFT/B3LYP [6-311G (d,p)] method. The optimized structure (ground state) is depicted in Fig. 1 and structural parameters (bond lengths, bond angles, and dihedral angles) are furnished in Tables 1 \& 2 . As exposed in Fig. 1, the molecular geometry of the parental pyrazole structural ornament has a typical butterfly form. The N25-H43, C17-Cl23, C19-Cl22, and C1-N4 bond lengths are $1.0071,1.7533,1.7533$ and $1.1549 \AA$ respectively agrees with the expected values $1.0(\mathrm{~N}-\mathrm{H}), 1.76(\mathrm{C}-\mathrm{Cl})$ and $1.16(\mathrm{CN})$. The bond angles between C8-C3-H33, C2-C3-C8, C3-C8-C9, and C3-C2-C24 are 114.233, 130.171, 130.124 and 127.719, respectively.

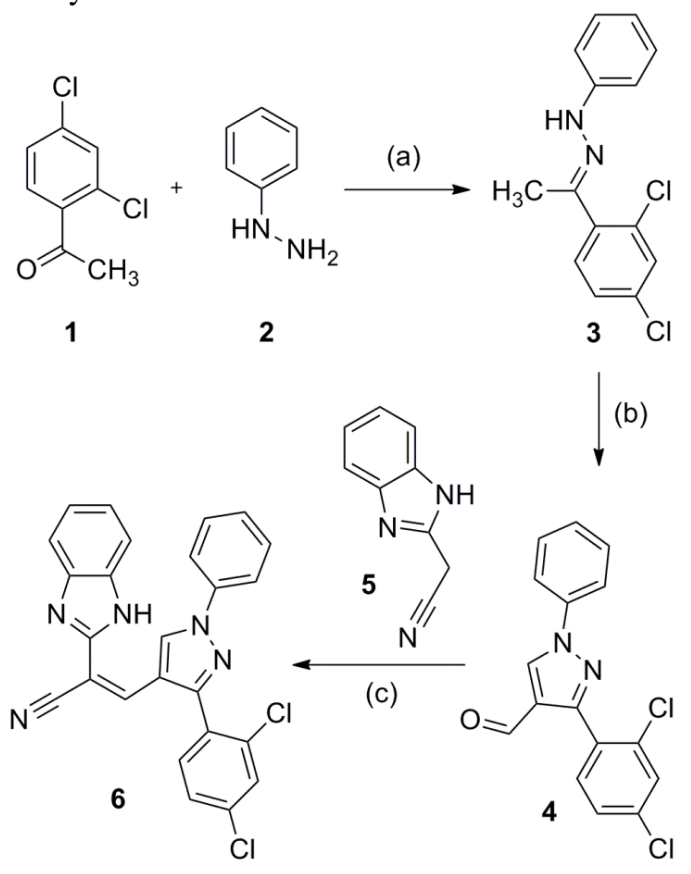

Scheme 1: Synthesis of target molecule 6. Reagents and conditions: (a) Glacial acetic acid, reflux, $30 \mathrm{~min}$; (b) DMF-POCl $\mathrm{I}_{3}, 70-80{ }^{\circ} \mathrm{C}, 6 \mathrm{~h}$; (c) Piperidine, methanol, 60 ${ }^{\circ} \mathrm{C}, 6 \mathrm{~h}$.

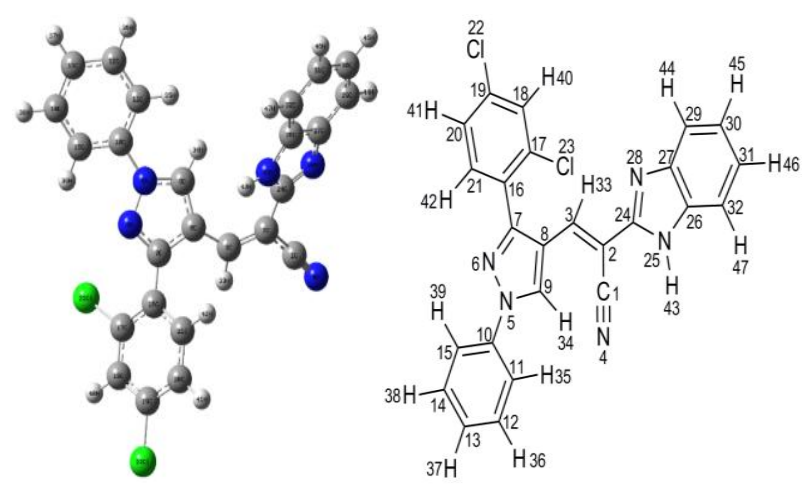

Fig. 1. Optimized Structure of 6

TABLE 1: BOND LENGTH OF 6

\begin{tabular}{lclc}
\hline $\begin{array}{l}\text { Bond } \\
\text { lengths }\end{array}$ & $(\AA)$ & Bond lengths & $(\AA)$ \\
\hline $\mathrm{C} 1-\mathrm{C} 2$ & 1.4335 & $\mathrm{C} 16-\mathrm{C} 17$ & 1.4046 \\
$\mathrm{C} 1-\mathrm{N} 4$ & 1.1549 & $\mathrm{C} 16-\mathrm{C} 21$ & 1.4029 \\
$\mathrm{C} 2-\mathrm{C} 3$ & 1.3607 & $\mathrm{C} 17-\mathrm{C} 18$ & 1.3915
\end{tabular}


International Journal of Engineering and Advanced Technology (IJEAT) ISSN: 2249 - 8958, Volume-9, Issue-1S4, December 2019

\begin{tabular}{llll} 
C2-C24 & 1.4675 & C17-C123 & 1.7533 \\
C3-C8 & 1.4488 & C18-C19 & 1.3892 \\
C3-H33 & 1.0852 & C18-H40 & 1.0808 \\
N5-N6 & 1.3536 & C19-C20 & 1.3896 \\
N5-C9 & 1.3564 & C19-C122 & 1.7533 \\
N5-C10 & 1.4251 & C20-C21 & 1.3885 \\
N6-C7 & 1.3249 & C20-H41 & 1.0816 \\
C7-C8 & 1.4356 & C21-H42 & 1.0833 \\
C7-C16 & 1.4759 & C24-N25 & 1.3831 \\
C8-C9 & 1.3899 & C24-N28 & 1.3126 \\
C9-H34 & 1.0760 & N25-C26 & 1.3812 \\
C10-C11 & 1.3959 & N25-H43 & 1.0071 \\
C10-C15 & 1.3957 & C26-C27 & 1.4154 \\
C10-C11 & 1.3959 & C26-C32 & 1.3947 \\
C10-C15 & 1.3957 & C27-N28 & 1.3808 \\
C11-C12 & 1.3917 & C27-C29 & 1.3998 \\
C11-H35 & 1.0829 & C29-C30 & 1.3869 \\
C12-C13 & 1.3927 & C29-H44 & 1.0829 \\
C12-H36 & 1.0836 & C30-C31 & 1.4086 \\
C13-C14 & 1.3939 & C30-H45 & 1.0837 \\
C13-H37 & 1.0835 & C31-C32 & 1.3898 \\
C14-C15 & 1.3904 & C31-H46 & 1.0839 \\
C14-H38 & 1.0837 & C32-H47 & 1.0839 \\
C15-H39 & 1.0810 & & \\
\hline & & &
\end{tabular}

TABLE 2: BOND ANGLE OF 6

\begin{tabular}{llll}
\hline Bond & [o] & Bond Angles & [] \\
Angles & & & \\
\hline C1-C2-C3 & 117.3249 & C16-C17-C18 & 121.5509 \\
C1-C2-C24 & 114.9401 & C16-C17-C123 & 121.4788 \\
C3-C2-C24 & 127.7186 & C18-C17-C123 & 116.9432 \\
C2-C3-C8 & 130.1709 & C17-C18-C19 & 119.2361 \\
C2-C3-H33 & 115.5713 & C17-C18-H40 & 120.1155 \\
C8-C3-H33 & 114.2332 & C19-C18-H40 & 120.6459 \\
N6-N5-C9 & 112.1044 & C18-C19-C20 & 121.1037 \\
N6-N5-C10 & 119.9915 & C18-C19-C122 & 119.1377 \\
C9-N5-C10 & 127.8950 & C20-C19-C122 & 119.7583 \\
N5-N6-C7 & 105.6323 & C19-C20-C21 & 118.6553 \\
N6-C7-C8 & 111.3188 & C19-C20-H41 & 120.4743 \\
N6-C7-C16 & 121.4943 & C21-C20-H41 & 120.8691 \\
C8-C7-C16 & 127.1523 & C16-C21-C20 & 122.3135 \\
C3-C8-C7 & 125.7543 & C16-C21-H42 & 118.6775 \\
C3-C8-C9 & 130.1238 & C20-C21-H42 & 118.9997 \\
C7-C8-C9 & 103.6365 & C2-C24-N25 & 123.3527 \\
N5-C9-C8 & 107.2959 & C2-C24-N28 & 124.0894 \\
N5-C9-H34 & 121.9375 & N25-C24-N28 & 112.4880 \\
C8-C9-H34 & 130.5823 & C24-N25-C26 & 107.1375 \\
N5-C10-C11 & 120.2499 & C24-N25-H43 & 125.8585 \\
N5-C10-C15 & 119.1463 & C26-N25-H43 & 126.8608 \\
C11-C10-C15 & 120.6037 & N25-C26-C27 & 104.5443 \\
C10-C11-C12 & 119.4433 & N25-C26-C32 & 132.9686 \\
C10-C11-H35 & 120.7421 & C27-C26-C32 & 122.4870 \\
C12-C11-H35 & 119.8055 & C26-C27-N28 & 110.2965 \\
C11-C12-C13 & 120.4170 & C26-C27-C29 & 119.8389 \\
C11-C12-H36 & 119.3362 & N28-C27-C29 & 129.864 \\
C13-C12-H36 & 120.2431 & C24-N28-C27 & 105.5299 \\
C12-C13-C14 & 119.6218 & C27-C29-C30 & 117.9713 \\
C12-C13-H37 & 120.1477 & C27-C29-H44 & 120.0614 \\
C14-C13-H37 & 120.2299 & C30-C29-H44 & 121.9669 \\
C13-C14-C15 & 120.6257 & C29-C30-C31 & 121.4197 \\
C13-C14-H38 & 120.0990 & C29-C30-H45 & 119.5950 \\
C15-C14-H38 & 119.2741 & C31-C30-H45 & 118.9850 \\
C10-C15-C14 & $119.2803 ~$ & C30-C31-C32 & 121.6675 \\
C10-C15-H39 & 119.1215 & C30-C31-H46 & 119.1625 \\
C14-C15-H39 & 121.5976 & C32-C31-H46 & 119.1699 \\
& & & \\
& &
\end{tabular}

\begin{tabular}{llll} 
C7-C16-C17 & 123.6723 & C26-C32-C31 & 116.6147 \\
C7-C16-C21 & 119.1921 & C26-C32-H47 & 122.1085 \\
C17-C16-C21 & 117.1352 & C31-C32-H47 & 121.2758 \\
\hline
\end{tabular}

\section{Mulliken charge distribution}

Mulliken population method yields the net atomic charge distribution of specific atoms in a molecule and thereby, the acceptor and donor pairs connecting the charge transfer in the molecule can be established [33, 34]. MEP analyses of $\mathbf{6}$ was attained from the optimized structural calculation and the results are given in Table 3 . The apparent atomic charge distribution of compound 6 is represented by coloring in Fig. 2. The net atomic charge distribution of compound is shown in Fig. 2. The output clearly indicates that the atom C24 of benzimidazole ring has got more positive charge due to electron-withdrawing character of nitrile moiety attached to the adjacent carbon atom and two neighboring electronegative nitrogen atoms. Also, the C7 atom of pyrazole ring holds almost nearer positive charge as that of C24 due to adjacent nitrogen atom, whereas the nitrogen N25 showed greater negative charges.

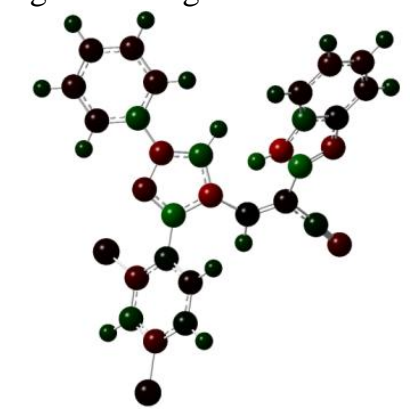

Fig. 2. Optimized Structure and Mulliken charge distribution of 6

Table 3. Mulliken atomic charges of 6

\begin{tabular}{cccc}
\hline Atom & Charges & Atom & Charges \\
\hline C1 & 0.074416 & N25 & -0.467867 \\
C2 & -0.036626 & C26 & 0.186284 \\
C3 & 0.003821 & C27 & -0.016192 \\
N4 & -0.220347 & N28 & -0.318904 \\
N5 & -0.337571 & C29 & -0.059183 \\
N6 & -0.218109 & C30 & -0.102555 \\
C7 & 0.294978 & C31 & -0.108248 \\
C8 & -0.414329 & C32 & -0.058206 \\
C9 & 0.228837 & H33 & 0.138563 \\
C10 & 0.208587 & H34 & 0.144945 \\
C11 & -0.108912 & H35 & 0.110456 \\
C12 & -0.099164 & H36 & 0.104865 \\
C13 & -0.078347 & H37 & 0.104076 \\
C14 & -0.098311 & H38 & 0.107065 \\
C15 & -0.060896 & H39 & 0.138675 \\
C16 & 0.035685 & H40 & 0.144074 \\
C17 & -0.208725 & H41 & 0.126993 \\
C18 & 0.148479 & H42 & 0.108412 \\
C19 & -0.237820 & H43 & 0.246255 \\
C20 & 0.029788 & H44 & 0.105149 \\
C21 & -0.045363 & H45 & 0.098377
\end{tabular}


Novel Benzimidazole Bejeweled Pyrazole: Synthesis, Characterization and Density Functional Theory Analysis

\begin{tabular}{cccc}
$\mathrm{Cl} 22$ & -0.046463 & $\mathrm{H} 46$ & 0.098213 \\
$\mathrm{Cl} 23$ & -0.046666 & $\mathrm{H} 47$ & 0.093148 \\
$\mathrm{C} 24$ & 0.308664 & & \\
\hline
\end{tabular}

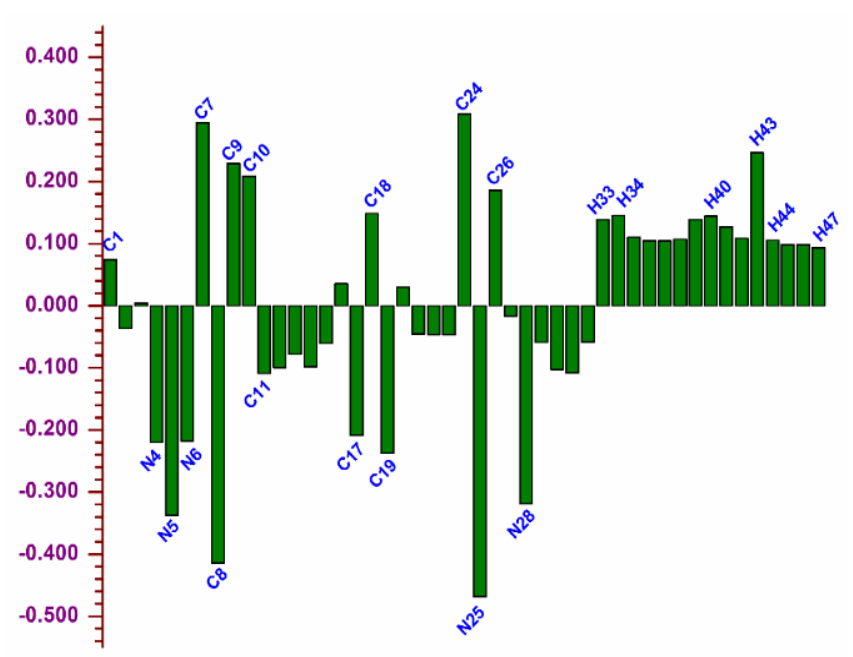

Fig. 3. Mulliken charge distribution of 6

\section{HOMO-LUMO Analysis}

The kinetic stability and chemical reactivity of a compound can be demonstrated based on the energy gap and localization of FMOs. HOMO-LUMO energy gap assist in determination of charge transport properties and electronic structure of a molecule [35]. Larger the difference between HOMO and LUMO greater will be the stability and chemical hardness. The electron distribution in the frontier molecular orbitals and their corresponding energy related values of the title acrylonitrile 6 are shown in Fig. 4 and Table 4 , respectively. HOMO orbitals are mostly located on the pyrazole ring and the LUMO orbitals are largely placed on the

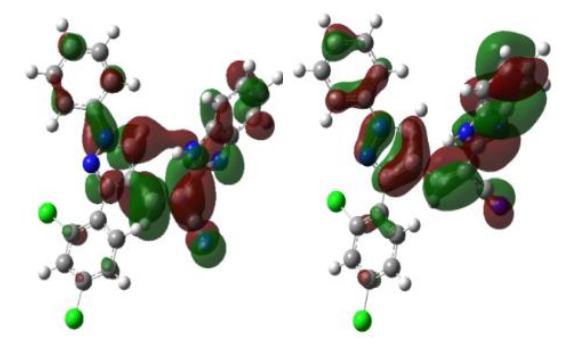

HOMO

LUMO
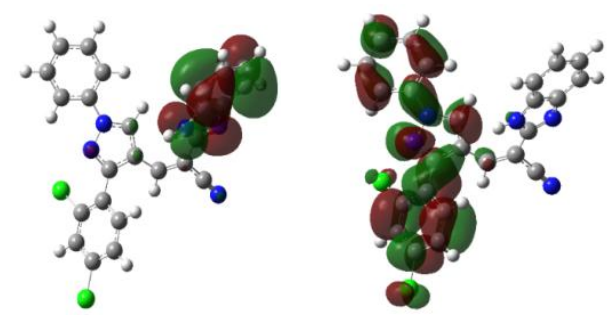

HOMO-1

$\mathrm{LUMO}+1$
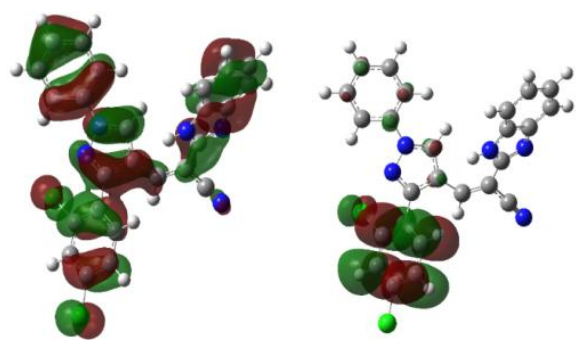

HOMO-2

$\mathrm{LUMO}+2$

Fig. 4. Frontier Molecular Orbitals of 6

benzimidazole and pyrazole moieties. However, the HOMO-1, LUMO+1, HOMO-2 and LUMO+2 molecular orbitals are located on benzimidazole scaffold, pyrazole ring and other phenyl rings attached to it, entire molecule and dichloro substituted phenyl ring, respectively thus, supporting intermolecular electron transfer.

Table 4. Energy distribution in FMO of 6

\begin{tabular}{ll}
\hline Parameters & $\mathrm{eV}$ \\
\hline HOMO & -6.3016 \\
LUMO & -2.5875 \\
$\Delta \mathrm{E}$ & 3.7141 \\
HOMO-1 & -6.7239 \\
LUMO+1 & -1.7894 \\
$\Delta \mathrm{E} 1$ & 4.9345 \\
HOMO-2 & -6.9354 \\
LUMO+2 & -1.2719 \\
$\Delta \mathrm{E} 2$ & 5.6635 \\
\hline
\end{tabular}

\section{E. Molecular electrostatic potential analysis}

The MEP predicts the reactivity of any molecule as it is related to electron density (ED) [36]. The MEP is supportive in identifying the locations for electrophilic and nucleophilic attack [37]. It is interpreted as a color spectrum (blue highest and red - lowest electrostatic potential). MEP map of 6 was resulted from optimized structural calculation.

The Fig. 5 shows the total density and electrostatic potential with its contour model of 6 ( $0.002 \mathrm{a} . \mathrm{u}$ isosurface). It could be observed from MEP images that the color code of the maps is in the range between $0.111 \mathrm{E}$ (nucleophilic attacking sites) and $-0.111 \mathrm{E}$ (electrophilic attacking site). The areas of red, high potential, are considered by abundance of electrons. From Fig 5, it is indicative that the nitrile (red) is most reactive site for electrophilic attack.

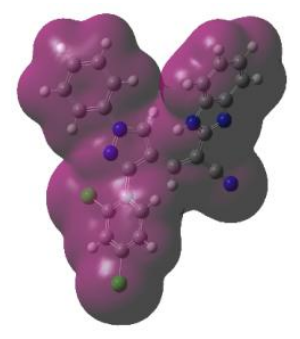

ED

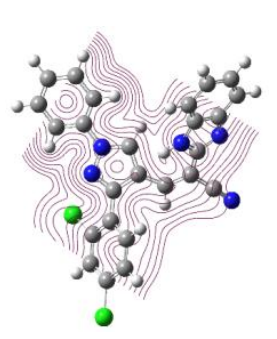

ED with contour 


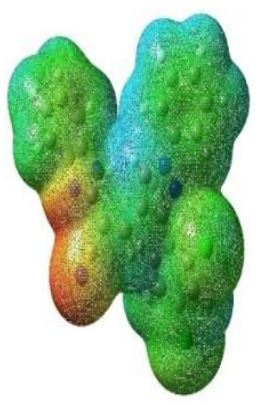

MEP

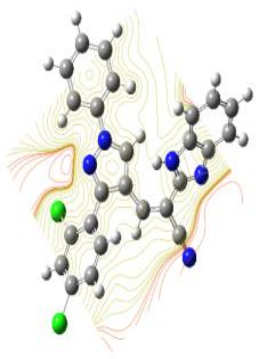

MEP with contour
Fig. 5. Molecular electrostatic potential map of 6

\section{F. Non-linear optical characteristics}

To realize the relation between NLO characteristics and molecular structure, the hyperpolarizabilities besides polarizabilities and dipole moments of 6 was calculated and the results are furnished in Table 5. It is documented that molecules with high values of hyperpolarizability, polarizability, and dipole moment exhibit potent NLO behaviors.

The total dipole moment (calculated one) is found to be 7.9778 Debye and average polarizability and hyperpolarizability are found to be $4.9128 \times 10-23$ Debye-Ang and 3.0902 x 10-30 esu, respectively. The hyperpolarizability of the synthesized molecule 6 is observed to be 3.8 times greater than urea molecule, a typical NLO material [38]. Thus, the compound 6 would be a promising NLO material.

Table 5. NLO Properties of 6

\begin{tabular}{ll}
\hline Parameters & Values \\
\hline Dipole moment & \\
$\mu_{\mathrm{x}}$ & -1.5194 \\
$\mu_{\mathrm{y}}$ & 6.7469 \\
$\mu_{\mathrm{z}}$ & -3.9769 \\
$\mu(\mathrm{D})$ & 7.9778 \\
Polarizability & \\
$\alpha_{\mathrm{xx}}$ & -191.1592 \\
$\alpha_{\mathrm{yy}}$ & -209.5043 \\
$\alpha_{\mathrm{zz}}$ & -204.0579 \\
$\alpha_{\mathrm{total}}$ & $4.9128 \times 10^{-23}$ \\
$\alpha_{0}$ & -201.5738 \\
Hyper-polarizability & \\
$\beta_{\mathrm{xxx}}$ & -86.5830 \\
$\beta_{\mathrm{xxy}}$ & 37.4778 \\
$\beta_{\mathrm{xyy}}$ & 25.0073 \\
$\beta_{\mathrm{yyy}}$ & 282.2245 \\
$\beta_{\mathrm{xxz}}$ & -13.6552 \\
$\beta_{\mathrm{xyz}}$ & 0.7472 \\
$\beta_{\mathrm{yyz}}$ & -68.8795 \\
$\beta_{\mathrm{xzz}}$ & 11.8297 \\
$\beta_{\mathrm{yzz}}$ & 18.4029 \\
$\beta_{\mathrm{zzz}}$ & -23.0823 \\
$\beta_{0}$ & $3.0902 \times 10^{-30}$ \\
\hline & \\
\hline
\end{tabular}

\section{CONCLUSION}

To summarize the present work, we have synthesized a novel acrylonitrile $\mathbf{6}$ and characterized. The quantum chemical parameters such as molecular geometry (bond angles and bond lengths), FMO, MEP, Mulliken charge distribution analyses and NLO properties of the novel molecule were computed. The small HOMO-LUMO energy gap and orbital localization indicated plausible inter electron transfer process, signifying the compound $\mathbf{6}$ has potential to be applied in the field of organic solar cells. Further, the predicted polarizability $\left(4.9128 \times 10^{-23}\right)$ and first order hyperpolarizability $\left(3.0902 \times 10^{-30}\right)$ values of the molecule are greater than urea. The result also signifies the compound $\mathbf{6}$ as a hopeful nonlinear optic material.

\section{ACKNOWLEDGMENT}

Financial assistance provided by the Indian Council of Medical research (No.58/16/2013-BMS), New Delhi, India is gratefully acknowledged.

\section{REFERENCES}

[1] C. Fernando, R-A. Andrés, I-M. María, E. T. John, M. F. Rodolfo, A Rodrigo, R. K. Alan, C. T. Juan, W. L. Christian, "Synthesis, structural characterization, and theoretical studies of new pyrazole (E)-2-\{[(5-(tert-butyl)-1H-pyrazol-3-yl)imino]methyl $\}$ phenol and (E)-2-\{[(1-(4-bromophenyl)-3-(tert-butyl)-1H-pyrazol-5-yl] imino] methyl \}phenol," J. Mol. Struc., vol. 1184, pp. 59-71, May 2019.

[2] R. Thomas, Y. S. Mary, K. S. Resmi, B. Narayana, B. K. Sarojini, G. Vijayakumar, C. Van Alsenoy, "Two neoteric pyrazole compounds as potential anti-cancer agents: Synthesis, electronic structure, physico-chemical properties and docking analysis," J. Mol. Struc., vol. 1181, pp. 455-466, April 2019.

[3] S. Samshuddin, B. Narayana, B. K. Sarojini, M. T. H. Khan, H. S Yathirajan, C. G. Darshan Raj, R. Raghavendra, "Antimicrobial, analgesic, DPPH scavenging activities and molecular docking study of some 1,3,5-triaryl-2-pyrazoline," Med. Chem. Res., vol. 21, pp. 2012-2022, August 2012.

[4] E. S. H. Ei-Ashry, L. F. Awad, E. I. Ibrahim, O. K. Bdeewy, "Synthesis of antipyrine derivatives derived from dimedone" Chinese J. Chem., vol. 25, pp. 570, April 2007

[5] N. Uramaru, H. Shigematsu, A. Toda, R. Eyanagi, S. Kitamura, S Ohta, "Design, Synthesis, and Pharmacological Activity of Nonallergenic Pyrazolone-Type Antipyretic Analgesics," J. Med. Chem., vol. 53, pp. 8727-8733, December 2010.

[6] A. M. Isloor, B. Kalluraya, M. Rao, "Sydnone derivatives: part IV; synthesis of 3-aryl-4-(substituted pyrazolidene hydrazine-4-thiazolyl) sydnones as possible analgesic and anticonvulsant agents," J. Saudi Chem. Soc, vol. 4, pp. 265-270, April 2000.

[7] E. Bansal, V. K. Srivastava, A. Kumar, "Synthesis and anti-inflammatory activity of 1-acetyl-5-substitute daryl-3-( $\beta$-aminonaphthyl)-2-pyrazolines and $\beta$-(substitute daminoethyl) amidonaphthalenes," Eur. J. Med. Chem., vol. 36, pp. 81-92, September 2001.

[8] A. A. Bekhit, T. Abdel-Aziem, "Design, synthesis and biological evaluation of some pyrazole derivatives as anti-inflammatory-antimicrobial agents," Bioorg. Med. Chem., vol.12, pp.1935-1945, April 2004.

[9] M. Youssef, E. G. Neeland, E. B. Villanueva, M. S. White, I. M. El-Ashmawy, B. Patrick, A. Klegeris, A. S. Abd-El-Aziz, "Synthesis and biological evaluation of novel pyrazole compounds," Bioorg. Med. Chem., 2010, vol. 18, pp. 5685-5696, August 2010.

[10] Sunil, A. M. Isloor, P. Shetty, "Synthesis, characterization and anticancer activity of 1, 2, 4-triazolo [3, 4-b]-1, 3, 4-thiadiazoles on Hep G2 cell lines," Der. Pharma. Chemica., vol. 1, pp. 19-26, June 2009. 
[11] J. Mohan, B. K. Sarojini, B. Narayana, G. Sanjeev, "Radioprotective effect of an edaravone analogue 3-methyl-1- (4-(trifluoromethyl) phenyl)-1,2-dihydropyrazol-5- one," Indo. Am. J. Pharm. Res., vol. 3 , pp. 1650-1659, December 2013.

[12] S. Rao, P. M. Akberali, B. S. Holla, B. K. Sarojini, "Synthesis and Studies on Some New Fluorine Containing Hydroxypyrazolines and $1 \mathrm{H}$ Pyrazoles-as Possible Antiproliferative Agents, J. Pharm and Toxic., vol. 3, pp. 102-110, 2008.

[13] Meta, C. Brullo, M. Tonelli, S. G. Franzblau, Y. Wang, R. Ma, W. Baojie, B. S. Orena, M. R. Pasca, O. Bruno, "Pyrazole and imidazo [1, 2-b] pyrazole Derivatives as New Potential Anti-tuberculosis Agents," Med. Chem., vol. 15, pp. 17-27, February 2019.

[14] Chiara B. Vicentini, Donatella Mares, Alfredo Tartari, Maurizio Manfrini, and Giuseppe Forlani, "Synthesis of pyrazole derivatives and their evaluation as photosynthetic electron transport inhibitors," $J$. Agri. Food Chem., 2004, vol. 52, pp. 1898-1906, February 2004.

[15] Zhang, D. Ma, R. Liu, L. Duan, "High-efficiency blue-green electroluminescence from sublimable cationic iridium (iii) complexes with a pyrazole-type ligand," J. Mater. Chem. C., vol. 7, pp. 3503-3511, February 2019.

[16] S. Mert, R. Kasimogullari, S. Ok, "A short review on pyrazole derivatives and their applications," J. Postdoc Research., vol.2, pp. 64-72, April 2014.

[17] Burschka, F. Kessler, M. K. Nazeeruddin and M. Gratzel, "Co(III) Complexes as p-Dopants in Solid-State Dye-Sensitized Solar Cells," Chem. Mater., vol. 25, pp. 2986-2990, June 2013.

[18] R. A. Senthil, J. Theerthagiri, J. Madhavan and A. K. Arof, "Influence of pyrazole on the photovoltaic performance of dye-sensitized solar cell with polyvinylidene fluoride polymer electrolytes," Ionics, vol. 22, pp. 425-433, March 2016.

[19] U. M. Kauhanka and M. M. Kauhanka, "Synthesis of new liquid crystalline isoxazole-, pyrazole-and 2-isoxazoline-containing compounds," Liq. Cryst., vol. 33, pp. 121-127 August 2006.

[20] H.-B. Liu, W.-W, Gao, V. K. R. Tangadanchu, C.-H. Zhou, R.-X. Geng, "Novel aminopyrimidinyl benzimidazoles as potentially antimicrobial agents: design, synthesis and biological evaluation," Eur. J. Med. Chem., vol. 143, pp. 66-84, January 2018.

[21] H. Göker, G. Ayhan-Kilcigil, M. Tunçbilek, C. Kus, R. Ertan, E. Kendi, S. Özbey, M. Fort, C. Garcia, A. J. Farré, "Synthesis and antihistaminic H1 activity of 1, 2, 5 (6)-trisubstituted benzimidazoles," Heterocycles, vol. 51, pp. 2561-2573, November 1999.

[22] M. Alp, H. Göker, R. Brun, S. Yıldız, "Synthesis and antiparasitic and antifungal evaluation of $2^{\prime}$-arylsubstituted-1H, 1' H-[2, 5'] bisbenzimidazolyl-5-carboxamidines," Eur. J. Med. Chem., vol. 44, pp. 2002-2008, May 2009.

[23] H. Nakano, T. Inoue, N. Kawasaki, H. Miyataka, H. Matsumoto, T. Taguchi, N. Inagaki, H. Nagai, T. Satoh, "Synthesis and biological activities of novel antiallergic agents with 5-lipoxygenase inhibiting action," Bioorg. Med. Chem., vol. 8, pp. 373-380, February 2000.

[24] Z. Hu, L. Ou, S. Li, L. Yang, "Synthesis and biological evaluation of 1-cyano-2-amino-benzimidazole derivatives as a novel class of antitumor agents," Med. Chem. Res., vol. 23, pp. 3029-3038, June 2014.

[25] G. Ayhan-Kılcıgil, S. Gürkan, T. Çoban, E. D. Özdamar, B. Can-Eke, "Synthesis and Evaluation of Antioxidant Properties of Novel 2-[2-(4-chlorophenyl)benzimidazole-1-yl]-N-(2-arylmethylene amino) acetamides and 2-[2-(4-chlorophenyl) benzimidazole-1-yl]-N-(4-oxo-2-aryl-thiazolidine-3-yl) acetamides-I," Chem. Biol. \& Drug Design., vol. 79, pp. 869-877, January 2012.

[26] Y. Qi, Y. Gao, S. Tian, A. R. Hlil, J.Gaudet, D. Guay, A. S. Hay, "Synthesis and properties of novel benzimidazole- containing sulfonated polyethersulfones for fuel cell applications," J. Polym. Sci. Part A: Polym. Chem., vol. 47, pp. 1920-1929, January 2009.

[27] G. Izzet, H. Akdas, N. Hucher, M. Giorgi, T. Prangé, O. Reinaud, "Supramolecular Assemblies with Calix[6]arenes and Copper Ions: from Dinuclear to Trinuclear Linear Arrangements of Hydroxo- $\mathrm{Cu}$ (II) Complexes," Inorg. Chem., vol. 45, pp. 1069-1077, January 2006.

[28] P. Díez, A. Sánchez, M. Gamella, P. Martínez-Ruíz, E. Aznar, C. De La Torre, et al, "Toward the design of smart delivery systems controlled by integrated enzyme-based biocomputing ensembles," J. Am. Chem. Soc., vol. 136, pp. 9116-9123, June 2014.

[29] P. Horcajada, R. Gref, T. Baati, P.K Allan, G. Maurin, P. Couvreur, et al, "Metal-organic frameworks in biomedicine," Chem. Rev., vol. 112 pp. 1232-1268, December 2011.

[30] S. Bansal, M. Bala, S. K. Suthar, S. Choudhary, S. Bhattacharya V. Bhardwaj, S. Singla, A. Joseph, "Design and synthesis of novel 2-phenyl-5-(1, 3-diphenyl-1H-pyrazol-4-yl)-1, 3, 4-oxadiazoles as

selective COX-2 inhibitors with potent anti-inflammatory activity," Eur. J. Med. Chem., vol. 80, pp. 167-174, June 2014.

[31] M. J. Frisch, G. W. Trucks, H. B. Schlegel, G. E. Scuseria, M. A. Robb, J. R. Cheeseman, et. al., Gaussian Inc., Wallingford CT, Gaussian 09, Revision D.01, 2009.

[32] C. Lee, W. Yang, R. G. Parr, Development of the Colle-Salvetti correlation-energy formula into a functional of the electron density, Phys. Rev. B., vol. 37, pp. 785-789, January 1988.

[33] R. S. Mulliken, "Electronic Population Analysis on LCAO-MO Molecular Wave Functions. I," J. Chem. Phys., 1955, vol. 23, pp. 1833-1840, December 1955.

[34] R. S. Mulliken, "Molecular Compounds and Their Spectra. V. Orientation in Molecular Complexes," J. Chem. Phys., vol. 23, pp. 1841-1846, December 1955.

[35] I. Fleming, "Frontier Orbitals and Organic Chemical Reactions," Wiley-Blackwell, New York, 1976.

[36] J. S. Murray, K. Sen, "Molecular Electrostatic Potentials, Concepts and Applications," Elsevier, Amsterdam, 1996.

[37] P. Politzer, P. R. Laurence, K. Jayasuriya, "Molecular electrostatic potentials: an effective tool for the elucidation of biochemical phenomena," Environ. Health Perspect., vol. 61, pp.191-202, September 1985 .

[38] S. F. Lópeza, M. P. Mezaa, F. T. Hoyosb, "Study of the nonlinear optical properties of 4-nitroaniline type compounds by density functional theory calculations: Towards new NLO materials," Comp. Theor. Chem., vol. 1133, pp. 25-32, June 2018.

\section{AUTHORS PROFILE}

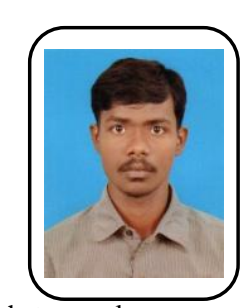

Ramar Sivaramakarthikeyan earned his BSc degree in Chemistry from VHNSN College, Virudhunagar, affiliated to Madurai Kamaraj University, Tamilnadu, India in 2013. He completed his MSc in Chemistry in 2015 from Kalasalingam Academy of Research and Education, Krishnankoil. Currently he is pursuing $\mathrm{PhD}$ at Kalasalingam Academy of Research and Education, Krishnankoil. $\mathrm{He}$ has been working in the area of biopertinent

heterocycles.

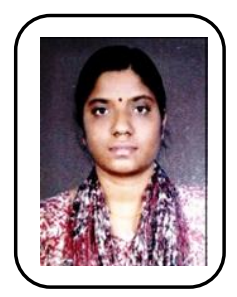

Krishnaraj Padmavathy received her Bachelor of Science degree in Chemistry from Bharathidasan college for women, Pondicherry in 2004. She obtained her Master's degree from Kanchi Mamunivar Centre for Postgraduate Studies, Pondicherry in 2006. She is currently a PhD student at Kalasalingam Academy of Research and Education, Krishnankoil, India. Her focus of research is methodology development and heterocyclic construction for biological applications.

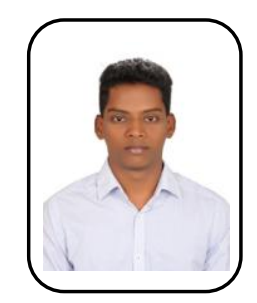

Vadivel Saravanan graduated (U.G.) from Madurai Kamaraj University, Madurai. He obtained his Masters degree in Chemistry from Kalasalingam Academy of Research and education, Krishnankoil $\mathrm{He}$ is currently a $\mathrm{PhD}$ student at Kalasalingam Academy of Research and education, Krishnankoil His research interest includes green chemistry and synthesis of novel materials for various applications.

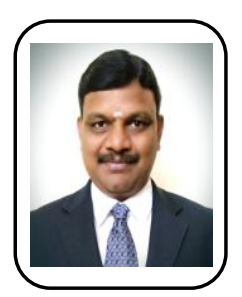

Dr. Chennan Ramalingan is serving as Professor of Chemistry at KARE. He received his PhD in Organic Chemistry from Annamalai University (2002). After he served as Research Professor at Kyungpook National University, South Korea followed by Assistant Professor at Osaka University, Japan (8 years), he joined at Kalasalingam Academy of Research and Education, Krishnankoil (2011). His research interests include organic synthesis, medicinal chemistry and material chemistry. $\mathrm{He}$ published more than 70 International research articles.

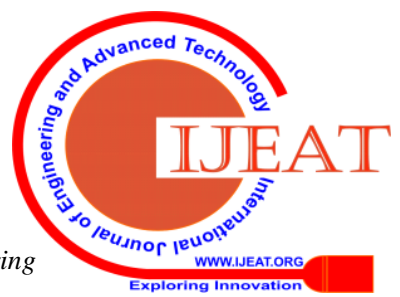

